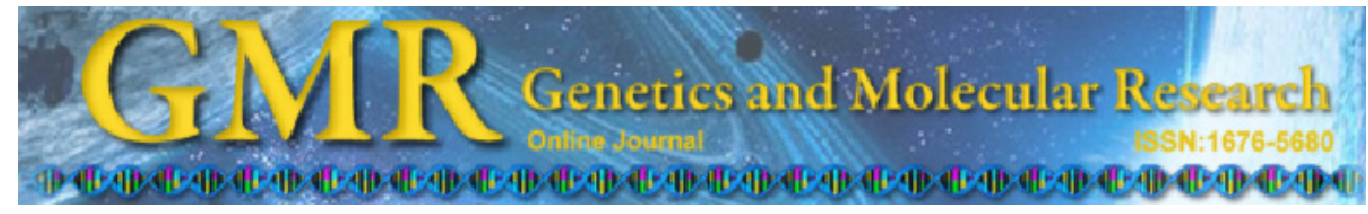

\title{
Molecular characterization of an opossum Didelphis albiventris (Marsupialia: Didelphidae) population in an urban fragment of the Brazilian Atlantic Rainforest and support to species barcode identification
}

L.C.C. Sousa ${ }^{1}$, C.M.F. Gontijo ${ }^{2}$, G.A. Lacorte ${ }^{1}$, S.N. Meireles ${ }^{1}$, A.P. Silva ${ }^{1}$ and C.G. Fonseca ${ }^{1}$

${ }^{1}$ Departamento de Biologia Geral, Instituto de Ciências Biológicas, Universidade Federal de Minas Gerais, Belo Horizonte, MG, Brasil ${ }^{2}$ Laboratório de Leishmanioses, Centro de Pesquisas René Rachou, Fundação Oswaldo Cruz, Belo Horizonte, MG, Brasil

Corresponding author: L.C.C. Sousa

E-mail: lucienecsousa@gmail.com

Genet. Mol. Res. 11 (3): 2487-2496 (2012)

Received September 8, 2011

Accepted October 17, 2011

Published June 15, 2012

DOI http://dx.doi.org/10.4238/2012.June.15.4

\begin{abstract}
We made a molecular study of 40 opossums, Didelphis albiventris, from an urban fragment of the Atlantic Rainforest in southeastern Brazil, analyzing a 653-bp sequence of cytochrome c oxidase, subunit I. We found three close connected haplotypes, with low nucleotide diversity and a haplotype diversity of $59.1 \%$ and confirmed sympatry between $D$. albiventris and $D$. aurita in this region. The clear phylogenetic separation shows the appropriateness of DNA barcode identification methodology for effectively discriminating between these opossum species.
\end{abstract}

Key words: Didelphis; Molecular characterization; Sympatry; Barcode; Cytochrome oxidase I 


\section{INTRODUCTION}

The white-eared opossum Didelphis albiventris Lund, 1840 has a wide distribution (Figure 1), occurring in Brazil, Paraguay, Uruguay, Argentina, Bolivia (Costa et al., 2008; Gardner, 2008), Ecuador, Peru, and Colombia (Wilson and Reeder, 2005). The Brazilian common opossum D. aurita Wied-Neuwied, 1826 also has widespread distribution and occurs in Brazil, Argentina, and Paraguay (Wilson and Reeder, 2005; Gardner, 2008) (Figure 1). Both D. albiventris and D. aurita are listed as "Least Concern" in the Red List Categories (Costa et al., 2008).

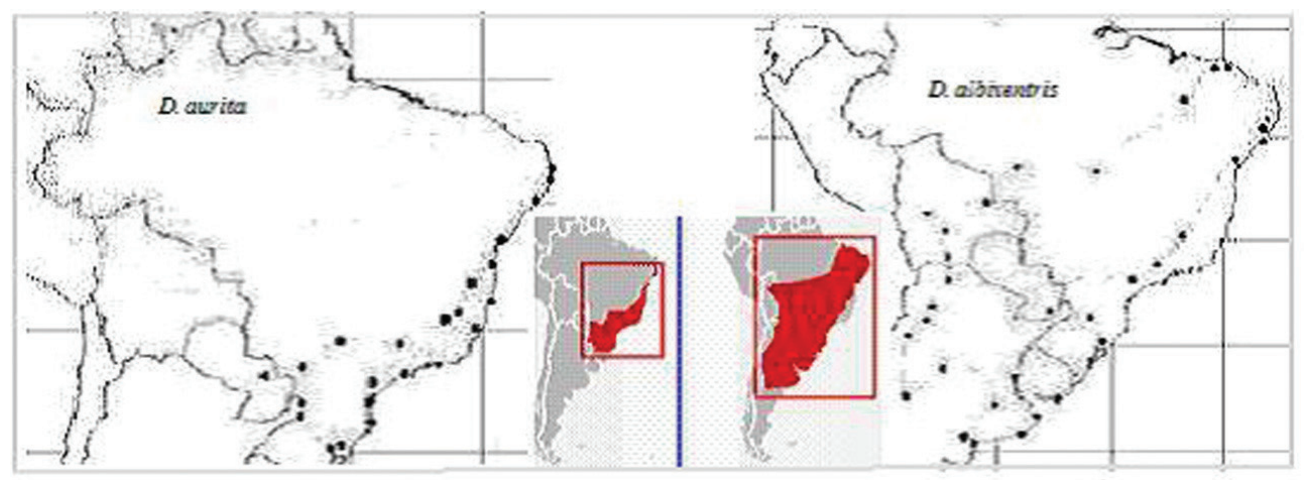

Figure 1. Map showing the distribution of Didelphis aurita and D. albiventris.

D. albiventris tolerates cultivated lands and their neighborhoods, deforested zones, and other disturbed places (Costa et al., 2008) and is found in many urban habitats, including major cities, revealing an ability to coexist with the disturbance caused by human exploitation of natural spaces.

Atlantic Forest is included in the biodiversity hotspot list (Mittermeier et al., 1998), and its biological uniqueness justifies and makes imperative the conservation of this biome (Chiarello, 2000). At present, the original forest territory includes enormous agricultural areas; urban and industrial centers, including the major Brazilian cities; and a vast populated contingent (about 110 million people). This has resulted in the reduction of the Atlantic Forest to less than $8 \%$ of its original area. Extensive mammalian diversity is observed, with 261 mammal species being found in this biome, of which 55 are endemic (Fundação SOS Mata Atlântica, 2011).

The distribution of $D$. albiventris overlaps with that of D. aurita one (Brito et al., 2008; Costa et al., 2008; Gardner, 2008), although sympatry records are not common. Sympatry between $D$. albiventris and D. aurita seems rare (Cerqueira, 1985; Gardner, 2008) but was found in disturbed areas (Varejão and Valle, 1982; Gardner, 2008). The distinction between $D$. aurita and $D$. albiventris opossum specimens is generally made on the basis of morphological characters such as the color of the ear and observed dentition patterns.

Exclusive maternal inheritance and high rates of nucleotide substitution contributed to the use of mtDNA as a molecular marker to trace the geographic distribution of genealogical lineages, even at the intra-specific level (Avise et al., 1987). Being useful for the accurate identification of specimens, the mtDNA conservative protein-coding gene cytochrome oxidase I (COI) has been selected as the marker for species discrimination by the Barcode of Life Database, 
which aims at sequencing a section of cytochrome oxidase I (COI) in all living species on Earth and generating a base for species identification (Folmer et al., 1994; Wilson-Wilde et al., 2010).

Remaining forest habitats persist as archipelagos of small forest fragments (Silva and Tabarelli, 2000), and the abundance and distribution of mammals decrease as the fragment becomes smaller (Chiarello, 2000; Pontes et al., 2007). Small mammalian species involved in the dispersion process are important for the maintenance of diverse forest ecosystems. Opossums can defecate viable seeds (Cáceres, 2002; Cantor et al., 2010) and play an important role as dispersors; this is especially true in urban forest fragments, where vegetation needs to be restored and the specialist frugivores are frequently absent (Cantor et al., 2010). Knowledge about Didelphis population biology is important for further understanding the involved ecosystems. Our objectives are to molecularly characterize the $D$. albiventris population of the analyzed Atlantic Forest urban fragment and to further molecularly support the previous morphological register of species sympatry between D. albiventris and D. aurita in Belo Horizonte Metropolitan Region (BHMR).

\section{MATERIAL AND METHODS}

\section{Sampling}

This study was developed under license for scientific purposes granted by IBAMA/ SISBIO, number 20170-2, which was renewed on February 2011. The institutions that collaborated with donations also have their own scientific licenses.

The analyzed area (Figure 2) is the capital of Minas Gerais state and part of its boundaries. Belo Horizonte is the sixth most populous Brazilian city, with 2,375,444 habitants and a demographic density of 7,167 hab $/ \mathrm{km}^{2}$ (Fundação SOS Mata Atlântica, 2011; IBGE, 2011).

Five localities in BHMR (Figure 2) were unequally sampled. D. albiventris samples were from Capitão Eduardo (32 specimens), Coração Eucarístico (3 specimens), Instituto Agronômico (2 specimens), Mangabeiras (1 specimen), and Jardim Canadá ( 2 specimens). A unique $D$. aurita specimen was collected from the Capitão Eduardo area. The approximate distances between the studied areas ranged from 6.5 to $26 \mathrm{~km}$.

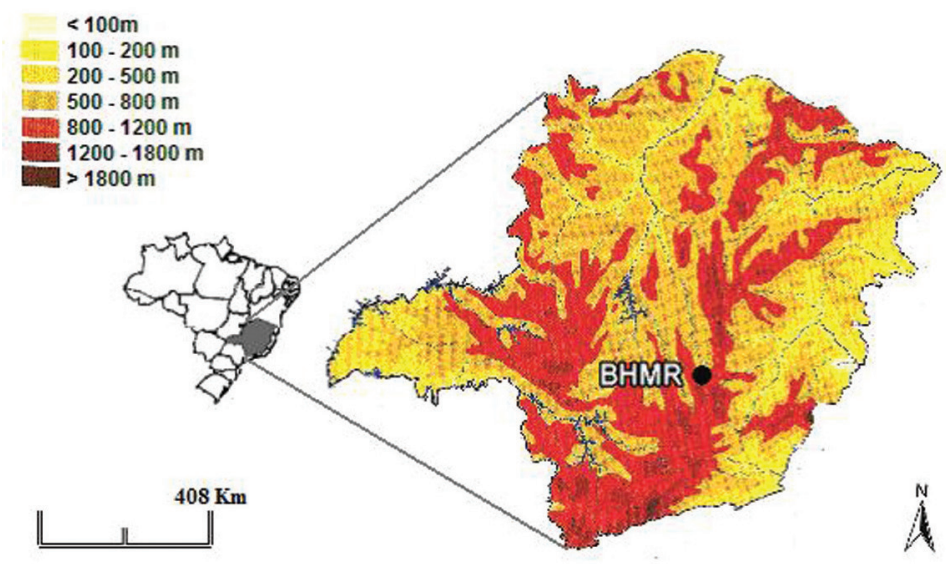

Figure 2. Minas Gerais Brazilian State, with a detach to Belo Horizonte Metropolitan Region (BHMR). 
DNA samples from these 41 BHMR opossums were analyzed, starting with the morphologically identified $40 \mathrm{D}$. albiventris and $1 \mathrm{D}$. aurita specimens. To determine the sympatry between the specimens, we used the barcode methodology. In this case, for comparison purposes, DNA samples from other areas were used: 3 D. albiventris individuals from Porto Alegre and Triunfo, Rio Grande do Sul (RS) State and from Xacriabá Reserve in Minas Gerais (MG) State; and 7 D. aurita individuals from Cotia and Ribeirão Grande in São Paulo (SP) State, Macaé in Rio de Janeiro (RJ) State, Conceição da Barra in Espírito Santo (ES) State, Serra do Ibituruna, Viçosa, and Piracema in Minas Gerais State. Linear geographic distances between BHMR and aforementioned areas range between 548 and $1364 \mathrm{~km}$ for D. albiventris and between 94 and $657 \mathrm{~km}$ for D. aurita. Distance data and collection point coordinates are shown in Table 1. Most samples were kindly donated by research institutions (Table 1). All studied sequences were developed in this study.

\begin{tabular}{|c|c|c|c|c|c|c|c|}
\hline Species & State & Locality/City & Distance to BHMR & $\mathrm{N}$ & Origin & South & West \\
\hline D. albiventris & MG & BHMR - Capitão Eduardo & - & 32 & CPqRR & $19^{\circ} 49^{\prime} 57^{\prime \prime}$ & $43^{\circ} 52^{\prime} 08^{\prime \prime}$ \\
\hline D. albiventris & MG & BHMR - Instituto Agronômico & - & 2 & Road Killed & $19^{\circ} 52^{\prime} 49^{\prime \prime}$ & $43^{\circ} 55^{\prime} 19^{\prime \prime}$ \\
\hline D. albiventris & MG & BHMR - Coração Eucarístico & - & 3 & MHN-PUC & $19^{\circ} 55^{\prime} 27^{\prime \prime}$ & $43^{\circ} 59^{\prime} 29^{\prime \prime}$ \\
\hline D. albiventris & MG & BHMR - Mangabeiras & - & 1 & Road Killed & $19^{\circ} 57^{\prime} 25^{\prime \prime}$ & $43^{\circ} 55^{\prime} 02^{\prime \prime}$ \\
\hline D. albiventris & MG & BHMR - Jardim Canadá & - & 2 & Road Killed & $20^{\circ} 03^{\prime} 04^{\prime \prime}$ & $43^{\circ} 58^{\prime} 10^{\prime \prime}$ \\
\hline D. albiventris & RS & Porto Alegre & $1343 \mathrm{~km}$ & 1 & FZB-RS & $29^{\circ} 56^{\prime} 34^{\prime \prime}$ & $51^{\circ} 43^{\prime} 13^{\prime \prime}$ \\
\hline D. albiventris & RS & Triunfo & $1364 \mathrm{~km}$ & 1 & FZB-RS & $30^{\circ} 01^{\prime} 41^{\prime \prime}$ & $51^{\circ} 13^{\prime} 43^{\prime \prime}$ \\
\hline D. albiventris & MG & Xacriabá Reserve & $548 \mathrm{~km}$ & 1 & CPqRR & $14^{\circ} 53^{\prime} 29^{\prime \prime}$ & $44^{\circ} 04^{\prime} 42^{\prime \prime}$ \\
\hline D. aurita & MG & BHMR - Capitão Eduardo & - & 1 & CPqRR & $19^{\circ} 49^{\prime} 57^{\prime \prime}$ & $43^{\circ} 52^{\prime} 08^{\prime \prime}$ \\
\hline D. aurita & SP & Cotia & $519 \mathrm{~km}$ & 1 & USP & $46^{\circ} 59^{\prime} 56^{\prime \prime}$ & $23^{\circ} 45^{\prime} 46^{\prime \prime}$ \\
\hline D. aurita & SP & Ribeirão Grande & $657 \mathrm{~km}$ & 1 & USP & $24^{\circ} 05^{\prime} 52^{\prime \prime}$ & $48^{\circ} 22^{\prime} 17^{\prime \prime}$ \\
\hline D. aurita & RJ & Macaé & $354 \mathrm{~km}$ & 1 & UFRJ & $22^{\circ} 22^{\prime} 18^{\prime \prime}$ & $41^{\circ} 47^{\prime} 08^{\prime \prime}$ \\
\hline D. aurita & ES & Conceição da Barra & $228 \mathrm{~km}$ & 1 & MBML & $18^{\circ} 35^{\prime} 29^{\prime \prime}$ & $39^{\circ} 44^{\prime} 06^{\prime \prime}$ \\
\hline D. aurita & MG & Serra do Ibituruna & $230 \mathrm{~km}$ & 1 & CPqRR & $18^{\circ} 44^{\prime} 56^{\prime \prime}$ & $42^{\circ} 13^{\prime} 00^{\prime \prime}$ \\
\hline D. aurita & MG & Viçosa & $145 \mathrm{~km}$ & 1 & UFV & $20^{\circ} 45^{\prime} 15^{\prime \prime}$ & $42^{\circ} 52^{\prime} 56^{\prime \prime}$ \\
\hline D. aurita & MG & Piracema & $94 \mathrm{~km}$ & 1 & CPqRR & $20^{\circ} 30^{\prime} 28^{\prime \prime}$ & $44^{\circ} 22^{\prime} 57^{\prime \prime}$ \\
\hline
\end{tabular}

\section{DNA extraction, DNA amplification, and sequencing}

We mostly used liver tissues and, in few cases, spleen and muscle tissues were used. For the road-killed animals, ear tissue fragments were collected. Tissue samples were preserved in $95 \%$ ethanol and stored in a freezer.

DNA from macerated tissue fragments was extracted following the standard phenolchloroform protocols, as described by Sambrook and Russel (2001).

DNA sequences of the mitochondrial COI gene were amplified using the universal primers LCO 1490: 5'-GGT CAA CAA ATC ATA AAG ATA TTG G-3' and HCO 2198: 5'TAA ACT TCA GGG TGA CCA AAA AAT CA-3' (Folmer et al., 1994). Each PCR were performed in a $20 \mu \mathrm{L}$ final volume containing $50 \mathrm{ng}$ genomic DNA, 10X buffer III B (Phoneutria ${ }^{\mathbb{B}}$; $100 \mathrm{mM}\left(\mathrm{NH}_{4}\right)_{2} \mathrm{SO}_{4}, 100 \mathrm{mM} \mathrm{KCl}, 100 \mathrm{mM}$ Tris- $\mathrm{HCl}, \mathrm{pH} 8.4,1 \%$ Triton-X, $15 \mathrm{mM} \mathrm{MgCl}$ ), $0.8 \mu \mathrm{M}$ dNTPs, $0.5 \mu \mathrm{M}$ of each primer, $1 \%$ bovine serum albumin (BSA), and $1 \mathrm{U}$ Taq DNA polymerase (Phoneutria ${ }^{\circledR}$ ). After an initial denaturing step of 3 min at $94^{\circ} \mathrm{C}$, the PCR conditions for the COI fragments followed a standard 3-step protocol, with 30 cycles of 1 ) denaturing for 1 min at $94^{\circ} \mathrm{C}, 2$ ) annealing for $45 \mathrm{~s}$ at $47^{\circ} \mathrm{C}$, and 3) extension for $30 \mathrm{~s}$ at $72^{\circ} \mathrm{C}$, followed by a final 
extension step for $5 \mathrm{~min}$ at $72^{\circ} \mathrm{C}$. Satisfactory amplifications were visualized on $6 \%$ polyacrylamide gels. Amplified DNA products were cleaned using 20\% polyethylene-glycol (PEG 8000) and $2.5 \mathrm{M} \mathrm{NaCl}$, according to the protocol reported by Sambrook and Russel (2001).

PCR products were sequenced in both directions by using the same primers: LCO 1490 or HCO 2198 (Folmer et al., 1994) on ABI3100 ${ }^{\mathbb{}}$ automated sequencer with the Applied Biosystems BigDye ${ }^{\circledR}$ Terminator Kit v3. Alternatively, some sequences were obtained on a MegaBACE automated capillary sequencer by using the GE Healthcare ET $^{\circledR}$ dye terminator kit.

\section{Statistical data analyses}

All mtDNA sequences were "base called" by using the Phred v.0.20425 software (Ewing et al., 1998; Ewing, 1998), checked for quality using the Phrap v.0.990319 software (Green, 1994), and the assembled chromatograms were verified and edited in Consed 12.0 (Gordon et al., 1998). Consensus was conferred with visual verification of chromatogram peaks. A sequence set with consensus was aligned using the Clustal $\mathrm{W}$ algorithm implemented in MEGA 4.1 (Kumar et al., 2007); a 653-bp fragment showed high levels of sequence quality for all individuals. All sequences were deposited in GenBank (accession Nos. JN638891-JN 638922; JN638976-JN638991).

MEGA 4.1 (Kumar et al., 2007), DNAsp v.5 (Librado and Rozas, 2009), and Arlequin v.3.1 (Schneider et al., 2000) was used to analyze intrapopulation genetic diversity and identify standard indices of genetic variation as haplotype diversity $(h)$ and nucleotide diversity $(\pi)$. MEGA 4.1 (Kumar et al., 2007) was used to visualize nucleotide variation and verify polymorphism coherence by using the translating approach.

Haplotype network was constructed on the basis of statistical parsimony by using TCS 1.21 (Clement et al., 2000). This method estimates the evolutionary relationships between haplotypes, connecting related ones and representing substitution steps between them.

Mismatch distribution and neutrality tests to verify excess of recent mutations as evidence of recent population expansion for BHMR D. albiventris population were performed in Arlequin v.3.1 (Schneider et al., 2000).

Phylogenetic inference was estimated using maximum parsimony, minimum evolution, Bayesian analyses, and neighbor joining models and analyzed using PAUP 4.0 (Swofford, 2002), Phy ML 3.0 (Guindon and Gascuel, 2003), MR BAYES (Huelsenbeck and Ronquist, 2001), and MEGA 4.1 (Kumar et al., 2007). The best evolutionary model was determined using Modeltest 3.7 (Posada and Crandall, 1998). The aim was to discriminate between $D$. albiventris and $D$. aurita specimens. In this context, barcode methodology was used to test the morphological register of sympatry and verify whether the molecular data support grounded the constatation of sympatry. Inter-specific variability was also studied.

For barcode discrimination, sequences for other localities (Table 1) were added to molecularly confirm the sympatry register.

\section{RESULTS}

For D. albiventris BHMR population, specimens from Capitão Eduardo (sub-area 1), Instituto Agronômico (sub-area 2), Coração Eucarístico (sub-area 3), Mangabeiras (sub-area 4), and Jardim Canadá (sub-area 5) were studied, with a maximum linear distance of about 26 
$\mathrm{km}$. The great majority, 32 specimens, were from Capitão Eduardo sub-area. Three different COI haplotypes were observed for BHMR D. albiventris population: haplotype 1 in sub-areas $1,3,4$, and 5; haplotype 2 in sub-areas 1, 2, and 5; and haplotype 3 in specimens from subareas 1 and 2.

BHMR D. albiventris database revealed 3 polymorphic sites, all corresponding to synonymous substitutions. Haplotype 1, the most frequent, was observed in 22 samples; haplotype 2 , in 13 individuals; and haplotype 3 , in 5 specimens. Haplotype diversity $(h)$ of 0.591 $( \pm 0.051)$, nucleotide diversity $(\pi)$ of 0.00185 , and an average number of nucleotide differences $(k)$ of 1.124 were found for BHMR population. Haplotype network showed a maximum of 3 steps between haplotypes within the D. albiventris group (Figure 3). Mismatch distribution and neutrality tests for verifying excess of recent mutations as evidence of recent population expansion showed non-significant $\mathrm{P}$ values for BHMR D. albiventris data.

\section{Pested Clade Phylogeographic Analysis}

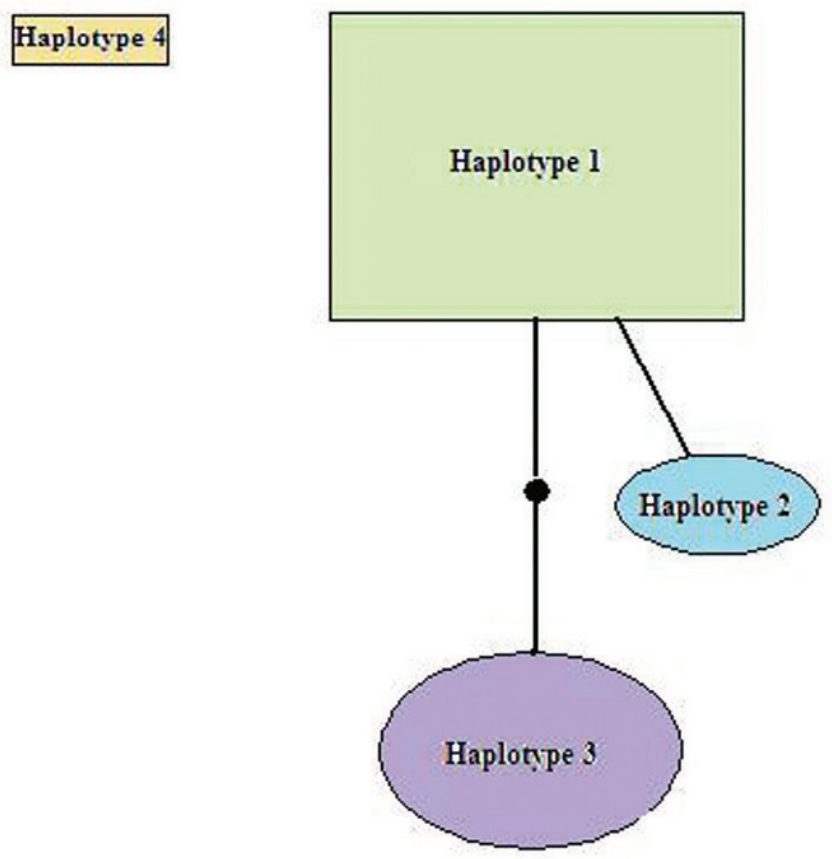

Figure 3. Haplotype network for 41 opossums collected in Belo Horizonte Metropolitan Region urban fragment.

When the same 653-bp COI fragment of the unique BHMR D. aurita sample was studied, a different haplotype was observed (haplotype 4). Adding a D. aurita specimen to the 40 specimens of $D$. albiventris from BHMR in an inter-specific analyses, 36 polymorphic sites were found, all corresponding to synonymous changes and 32 showing fixed differences. There was an average number of 33.25 nucleotide differences and a nucleotide divergence of 0.05439 between the species. 
BHMR opossum haplotype network (Figure 3) exhibited 4 haplotypes, 2 of which were identified as probable ancestral (D. albiventris haplotype 1 and $D$. aurita haplotype 4).

The HKY 85 evolutionary model of nucleotide substitution was the most appropriate for the analyzed dataset, as revealed by the Akaike informative criterion in Modeltest 3.7 (Posada and Crandall, 1998) analyses.

Phylogenetic relationships revealed by tree topologies of BHMR opossums were concordant to morphological identification. D. albiventris haplotype 1 was separated from $D$. aurita haplotype 4 by a large connection length of 35.64 (Table 2) compared to the largest connection length for $D$. albiventris intra-specific haplotypes, which was 2.01 . The results from our sequence analysis are unambiguous.

\section{Table 2. Connection length between 4 Belo Horizonte Metropolitan Region opossum haplotypes.}

\begin{tabular}{lc}
\hline Haplotype comparison & Connection length \\
\hline Haplotype 1 x Haplotype 2 & 2.01 \\
Haplotype 1 x Haplotype 3 & 1.00 \\
Haplotype 1 x Haplotype 4 & 35.64 \\
\hline
\end{tabular}

Three D. albiventris and 07 D. aurita (Table 1) specimens from other localities were included in our initial database of 40 BHMR D. albiventris and 01 BHMR D. aurita for comparison to test the sympatry register with the barcode methodology (Figure 4). For this dataset, 8 haplotypes, nucleotide diversity of 0.01773 , and haplotype diversity of 0.74 were observed. Inter-specific analyses revealed 46 polymorphic sites, all of which were synonymous substitutions; 24 fixed inter-species differences; and no shared substitutions. A nucleotide diversity ( $\pi$ total) of 0.00444 , an average number of nucleotide differences of 32.881 and a nucleotide divergence of 0.05399 , was observed.

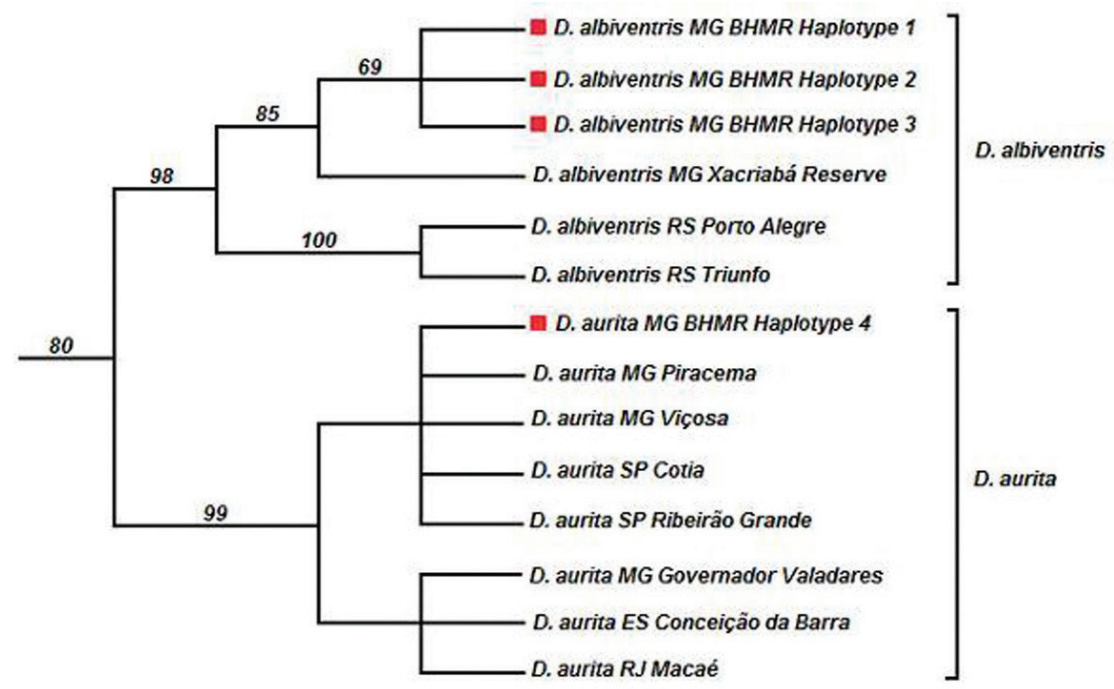

Figure 4. Maximum parsimony tree with Didelphis albiventris and D. aurita specimens from different geographic localities. 
Phylogeny inference was estimated using different evolutive models (neighbor joining, maximum likelihood, maximum parsimony, and Bayesian) returned similar results. The proposal topologies showed a clear separation between the studied species, as expected, suggesting that it is possible to discriminate $D$. albiventris and $D$. aurita specimens by using the studied mtDNA COI fragment. Phylogeny revealed 2 genetic clusters, each of which corresponded to a different opossum species, being completely concordant with previous morphological identification. BHMR D. aurita grouped with $D$. aurita from other localities, showing a perfect separation between opossum species and confirming local BHMR sympatry.

\section{DISCUSSION}

Opossums are habitat generalists and can move easily between forest fragments (high vagility) (Chiarello, 2000; Pires et al., 2002), showing a greater movement rate compared to other small mammals (Pires et al., 2002). The coverage of their distribution includes agricultural and urban places. Therefore, Didelphis seems to be an unique population when different fragments on a continuous area are analyzed, which is because of the ecological characteristics of opossums, such as the ability to move long distances (Gentile and Cerqueira, 1995) and the generalist habitat (Paglia et al., 1995; Passamani, 1995; Emmons and Feer, 1997). Radiotelemetry revealed a mean home range size of 122.7 ha for males and 12 ha for females of $D$. marsupialis (closely related to D. aurita) in Venezuela (Sunquist et al., 1987). The present data possibly represent a comprehensive geographic context, which can be tested in future studies in other geographic areas. Haplotype frequencies were 55\% for haplotype 1, 32.5\% for haplotype 2, and $12.5 \%$ for haplotype 3 ; hence, no rare haplotype was observed, and there was no evidence of population expansion or contraction. Mismatch distribution showed nonsignificant $\mathrm{P}$ values for BHMR D. albiventris data.

The haplotype distribution, with the same form (haplotype 1) shared by different BHMR areas, indicates that even with streets characterized by intense urban traffic and consequent high rates of road-killed animals, about $26 \mathrm{~km}$ of linear distance seems to be a small area when opossum ecological characteristics are considered, suggesting that it was necessary to analyze 40 BHMR $D$. albiventris specimens as a single population. Hence, haplotype distribution and occurrence indicates population unity. The BHMR D. albiventris population returned a haplotype network with 3 closely connected haplotypes, with a maximum of 3 steps of separation between haplotypes (Figure 3).

The molecular diagnosis results are in accordance with morphological identification, as expected, confirming $D$. albiventris and $D$. aurita sympatry in the urban Atlantic forest fragment. DNA barcode method was successfully used previously with opossums to effectively identify $D$. marsupialis and $D$. virginiana species from areas of sympatry in Mexico (Cervantes et al., 2010). Haplotype network (Figure 2) constructed using BHMR opossums showed 4 haplotypes, 2 of which were identified as probably ancestral (haplotype 1 and haplotype 4). Ancestral haplotypes were not linked to each other; such a linkage would require many steps and hence highly improbable. The occurrence of 2 ancestral forms in the haplotype network indicates the presence of 2 isolated genetic clusters. Absence of haplotype connection between haplotype 4, morphologically identified as D. aurita, and the others, clearly indicated a genetic distance between them. This indicated absence or near absence of gene flow.

Sympatry between opossums in Brazil was previously reported between $D$. albiven- 
tris and D. marsupialis in Curitiba (Cáceres and Monteiro-Filho, 1999). D. aurita was considered as a disjunct population of $D$. marsupialis until Cerqueira (1985) proposed species separation (Corbet and Hill, 1991). BHMR D. aurita grouped with $D$. aurita from other localities and was clearly separated from $D$. albiventris individuals, confirming the sympatry between these opossum species in BHMR and highlighting the potential of COI barcode analysis to discriminate specimens.

Thus, molecular characterization of BHMR D. albiventris population produced a haplotype network with 3 closely connected haplotypes, and haplotype distribution and occurrence indicated population unity. Our findings confirm sympatry between $D$. albiventris and $D$. aurita in the studied area. A clear separation between species enabled doubtless barcode identification for phylogenetic analyses with COI sequences, indicating the usefulness of barcode methodology to effectively discriminate opossums in the Atlantic forest region.

\section{ACKNOWLEDGMENTS}

We are grateful to Centro de Pesquisa René Rachou (CPqRR)-FioCruz, specially to Célia Gontijo, José Eloy dos Santos Júnior, and Helbert Botelho; to Pontifícia Universidade Católica de Minas Gerais-Museu de Ciências Naturais (MCN-PUC), Edeltrudes Câmara, Cláudia Costa, and Danilo Saraiva; to Museu de Biologia Professor Mello Leitão (MBML), Luisa Sarmento and Helio Boudet Fernandes; to Fundação Zoo-Botânica do Rio Grande do Sul (FZB-RS), Daniela Sanfelice; to Universidade de São Paulo (USP), Renata Pardini; to Universidade Federal do Rio de Janeiro (UFRJ), Campus Macaé, Pablo Rodrigues Gonçalves, and to Universidade Federal de Viçosa (UFV)-Museu de Zoologia João Moöjen, Gisele Lessa for specimen donations made to this research. Research supported by Fundação de Amparo à Pesquisa de Minas Gerais (FAPEMIG) and Programa de Ecologia de Longa Duração (PELD).

\section{REFERENCES}

Avise JC, Arnold J, Ball RM and Bermingham E (1987). Intraspecific phylogeography: The mitochondrial DNA bridge between population genetics and systematics. Annu. Rev. Ecol. Syst. 18: 489-522.

Brito D, Astúa de Moraes D, Lew D and Soriano P (2008). Didelphis aurita IUCN Red List of Threatened Species. Version 2011.1. Available at [http://www.iucnredlist.org]. Accessed July 31, 2011.

Cáceres NC (2002). Food habits and seed dispersal by the white-eared opossum, Didelphis albiventris, in the southern Brazil. Stud. Neotrop. Fauna Environ. 37: 97-104.

Cáceres NC and Monteiro-Filho ELA (1999). Body size in natural populations of Didelphis (Mammalia: Marsupialia) from southern Brazil. Rev. Bras. Biol. 59: 461-469.

Cantor M, Ferreira LA, Silva WR and Setz EZF (2010). Potential seed dispersal by Didelphis albiventris (Marsupialia, Didelphidae) in highly disturbed environment. Biota Neotrop. 10: 45-51.

Cerqueira R (1985). The distribution of Didelphis in South America (Polyprotodontia, Didelphidae). J. Biogeogr. 12: 135-145.

Cervantes FA, Arcangeli J, Hortelano-Moncada Y and Borisenko AV (2010). DNA barcodes effectively identify the morphologically similar Common Opossum (Didelphis marsupialis) and Virginia Opossum (Didelphis virginiana) from areas of sympatry in Mexico. Mitochondrial DNA 21 (Suppl 1): 44-50.

Chiarello AG (2000). Density and population size of mammals in remnants of Brazilian Atlantic Forest. Conserv. Biol. 14: 1649-1657.

Clement M, Posada D and Crandall KA (2000). TCS: a computer program to estimate gene genealogies. Mol. Ecol. 9: $1657-1659$.

Corbet GB and Hill JE (1991). A World List of Mammalian Species. 3rd edn. Oxford University Press, Oxford.

Costa L, Astúa de Moraes D, Brito D and Soriano P (2008). Didelphis albiventris IUCN Red List of Threatened Species. 
Version 2010.4. Available at [http://www.iucnredlist.org]. Accessed July 31, 2011.

Drummond GM, Martins CS, Machado ABM, Sebaio FA, et al. (2005). Biodiversidade em Minas Gerais: Um Atlas para sua Conservação. $2^{\mathrm{a}}$ ed. Fundação Biodiversitas, Belo Horizonte.

Emmons LH and Feer F (1997). Neotropical Rainforest Mammals: A Field Guide. 2nd edn. The University of Chicago Press, Chicago.

Ewing B and Green P (1998). Base-calling of automated sequencer traces using phred. II. Error probabilities. Genome Res. 8: 186-194.

Ewing B, Hillier L, Wendl MC and Green P (1998). Base-calling of automated sequencer traces using phred. I. Accuracy assessment. Genome Res. 8: 175-185.

Folmer O, Black M, Hoeh W, Lutz R, et al. (1994). DNA primers for amplification of mitochondrial cytochrome c oxidase subunit I from diverse metazoan invertebrates. Mol. Mar. Biol. Biotechnol. 3: 294-299.

Fundação SOS Mata Atlântica (2011). Fundação SOS Mata Atlântica Web Services. Available at [http://www. sosmatatlantica.org.br]. Accessed July 31, 2011.

Gardner AL (2008). Mammals of South America. Vol. 1: Marsupials, Xenarthrans, Shrews and Bats. The University of Chicago Press, Chicago.

Gentile R and Cerqueira R (1995). Movement patterns of five species of small mammals in a Brazilian restinga. J. Trop. Ecol. 11: 671-677.

Gordon D, Abajian C and Green P (1998). Consed: a graphical tool for sequence finishing. Genome Res. 8: 195-202.

Green P (1994). Phrap. Available at [http://www.genome.washington.edu/UWGC/analysistools/phrap.htm]. Accessed July 31, 2011.

Guindon S and Gascuel O (2003). A simple, fast, and accurate algorithm to estimate large phylogenies by maximum likelihood. Syst. Biol. 52: 696-704.

Huelsenbeck JP and Ronquist F (2001). MRBAYES: Bayesian inference of phylogenetic trees. Bioinformatics 17: 754755.

IBGE (2011). Instituto Brasileiro de Geografia e Estatística Web Services. Available at [http://www.ibge.gov.br]. Accessed July 31, 2011.

Kumar S, Tamura K and Nei M (2007). MEGA4 (Molecular Evolutionary Genetics Analysis). Ver. 4.0. [Computer Software]. Arizona State University, Tempe.

Librado P and Rozas J (2009). DnaSP v5: A software for comprehensive analysis of DNA polymorphism data. Bioinformatics 25: 1451-1452.

Mittermeier RA, Myers N, Thomsen JB and Fonseca GAB (1998). Biodiversity hotspots and major tropical wilderness areas: approaches to setting conservation priorities. Conserv. Biol. 12: 516-520.

Paglia AP, De Marco P Jr, Costa FM and Pereira RF (1995). Heterogeneidade estrutural e diversidade de pequenos mamíferos em um fragmento de mata secundária de Minas Gerais. Rev. Bras. Zool. 12: 67-79.

Passamani M (1995). Vertical stratification of small mammals in Atlantic Hill forest. Mammalia 59: 276-279.

Pires AS, Lira PK, Fernandez FAS and Schittini GM (2002). Frequency of movements of small mammals among Atlantic Coastal Forest fragments in Brazil. Biol. Conserv. 108: 229-237.

Pontes ARM, Normande IC, Fernandes ACA and Ribeiro PFR (2007). Fragmentation causes rarity in common marmosets in the Atlantic forest of northeastern Brazil. Biodivers. Conserv. 16: 1175-1182.

Sambrook J and Russel DW (2001). Molecular Cloning: A Laboratory Manual. Cold Spring Harbor Laboratory Press, Cold Spring.

Schneider S, Roessli D and Excoffier L (2000). ARLEQUIN Version 3.01: A Software for Population Genetic Data Analysis. Genetics and Biometry Laboratory, University of Geneva, Switzerland.

Silva JMC and Tabarelli M (2000). Tree species impoverishment and the future flora of the Atlantic forest of northeast Brazil. Nature 404: 72-74.

Sunquist ME, Austad N and Sunquist F (1987). Movement patterns and home range in the common opossum (Didelphis marsupialis). J. Mammal. 68: 173-176.

Swofford D (2002). PAUP*: Phylogenetic Analysis Using Parsimony (and other methods). Computer software. Version 4. Sinauer Associates, Sunderland.

Varejão JBM and Valle CMC (1982). Contribuição ao estudo da distribuição geográfica do gênero Didelphis (Mammalia: Marsupialia) no Estado de Minas Gerais, Brasil. Lundiana 2: 5-55.

Wilson-Wilde L, Norman J, Robertson J, Sarre S, et al. (2010). Current issues in species identification for forensic science and the validity of using the cytochrome oxidase I (COI) gene. Forensic Sci. Med. Pathol. 6: 233-241.

Wilson DE and Reeder DAM (2005). Mammal Species of the World: A Taxonomic and Geographic Reference. Vol. 1. 3rd edn. The Johns Hopkins University Press, Baltimore. 